\title{
Effect of tamoxifen treatment at adolescent age on the sexual behaviour and steroid hormone receptor binding of adult female rats
}

\author{
G. Csaba ${ }^{1}$, Cs. Karabélyos ${ }^{2}$, Ágnes Inczefi-Gonda ${ }^{1}$ \\ ${ }^{1}$ Department of Genetics, Cell- and Immunobiology, Semmelweis University, Budapest and \\ ${ }^{2}$ BIOTEST Hungaria Ltd., Budapest, Hungary
}

Received: August 24, 2001

Accepted: October 10, 2001

\begin{abstract}
Hormonal imprinting takes place perinatally, at the first encounter between the target hormone and its developing receptor. However, there is a secondary critical period of imprinting at puberty. In these periods molecules similar to the hormones (members of the same hormone family, antagonists, certain environmental pollutants, etc.) can cause faulty imprinting with lifelong consequences. In the present experiments 5+2 days of tamoxifen treatment ( $120 \mu \mathrm{g} / \mathrm{day})$ at adolescent age dramatically (from approx. $40 \%$ to $10 \%$ ) reduced the sexual activity (Meyerson index and lordosis quotient) of female rats, soon after the finishment of the treatment and between four to six weeks after treatment. Similar results were observed in animals neonatally treated with allylestrenol and tamoxifen treated at puberty. Thymic glucocorticoid receptor and uterine estrogen receptor binding capacity were not influenced.
\end{abstract}

Keywords: estrogen receptors, glucocorticoid receptors, hormonal imprinting, sexual behavior, Tamoxifen

Hormonal imprinting takes place perinatally, when the target hormone meets the developing receptor (4-6). As a consequence of imprinting the receptors reach the binding capacity which is characteristic to the adult age $(7,8)$, however without imprinting this binding capacity remains weaker (10). In the critical imprinting period molecules resembling to the target hormone (hormone analogues, members of the same hormone family, environmental pollutants with hormone-like character, antihormones,

Correspondence should be addressed to

G. Csaba MD, PhD, DSc, Professor Emeritus

Department of Genetics, Cell- and Immunobiology

Semmelweis University

H-1445 Budapest, P.O. Box 370, Hungary

Fax: (36-1) 210-2950

E-mail: csagyor@dgci.sote.hu 
etc.) can cause faulty imprinting with lifelong disturbed receptor binding and response of the receptor bearing cell $(1-3,7-9,17,18,20,25)$. However, though in case of steroid hormones the first days of life are the postnatal critical periods, in some cases there is a possibility for provoking imprinting in adolescents, as it was demonstrated by using nandrolone, the administration of which developed a decrease of thymic and uterine receptor binding capacity (density) in adult age (11).

Tamoxifen is a synthetic non-steroid antiestrogen (e.g. in case of breast), which sometimes (mainly in skeletal and cardiovascular tissues) mimics estrogen effects (19, 21). Single neonatal treatment with tamoxifen practically nullifies sexual response to males in adult female animals (12) and decreases the binding capacity of adult's thymic glucocorticoid and uterine estrogen receptors (13). These observations make reasonable to study the effect of pubertal tamoxifen treatment on the behavioral and receptorial parameters. Considering that investigations on animals which were imprinted with allylestrenol - a progestagene steroid, which was (is) used for protecting endangered pregnancies - have a practical use, we also studied the tamoxifen effect on that kind of animals.

\section{Materials and Methods}

\section{Animals and treatment}

Newborn female rats of our closed bred Wistar strain were treated with $17.5 \mu \mathrm{g}$ allylestrenol (Richter, Budapest, Hungary) suspended in $0.2 \mathrm{ml}$ sunflower seed oil, within $24 \mathrm{~h}$ after birth, subcutaneously. Controls were treated with the oil only. When the animals were ten weeks old, tamoxifen (Sigma, USA, $60 \mu \mathrm{g} /$ day) treatment was administered for $5+2$ days (during week-end the animals was not treated) and $24 \mathrm{~h}$ after the last treatment the females were tested for sexual behavior. Two weeks after the finishment of the first testing (4 to 6 weeks after finishing the tamoxifen treatment) the testing was repeated. When the animals were 5 and a half months old, uteri and thymi were studied for receptors 8 days after ovariectomy. Three thymi or four uteri were homogenized for winning one preparation for one measurement. All assays were performed in duplicate. Data (means) resulted from measurements of 3-5 different homogenates in each group.

\section{Sexual-behavioral study of female animals}

The receptivity of female rats was measured by the help of indicator (experienced) males. Two parameters were recorded for the evaluation of receptivity, 
the Meyerson index and the lordosis quotient. The former gives a binary answer for the appearance of the lordotic response on the first mounting of the male (22). The latter is a ratio of the lordosis percent in ten mountings $(\mathrm{L} / \mathrm{M})$. For comparable results the females within the two week-study were screened only during estrus (the correct timing was made by vaginal smears). In each group five-six animals were tested a day.

The average of the daily data were used for evaluating significance with Student $t$ - and $\chi^{2}$-tests.

\section{Preparation of cytosol fraction for receptor assays}

All procedures were performed at ice/water temperature. Tissues examined were cut into pieces and homogenized in Tris- $\mathrm{HCl}$ buffer-containing $1.5 \mathrm{mM}$ EDTA, pH 7.4 (freshly supplemented with $20 \mathrm{mM}$ molybdate and $2 \mathrm{mM}$ dithiotreitol) with a motor driven glass-teflon Potter homogenizer $1.5 \mathrm{ml} / \mathrm{g}$ wet weight. Homogenates were centrifuged at 100,000 $\mathrm{g}$ for $60 \mathrm{~min}$ at $4{ }^{\circ} \mathrm{C}$ and the supernatants were used for receptor assays. Protein content was estimated by Coomassie-blue method.

\section{Glucocorticoid receptor - thymus cytosol}

$500 \mu \mathrm{g}$ protein was incubated with $10,5,2.5,1.25,0.6,0.3$ and $0.15 \mathrm{nM}{ }^{3} \mathrm{H}-$ dexamethasone (Amersham, Buckinghamshire, England; spec. act. $1.8 \mathrm{TBq} / \mathrm{mmole}$ ) in the absence or in the presence of 1000-fold molar excess of unlabeled ligand (Sigma, USA) in a total volume of $100 \mu \mathrm{l}$ at $0{ }^{\circ} \mathrm{C}$ for 18 hours. Bound glucocorticoid was separated by the charcoal method and counted in OptiPhase, HiSafe (Pharmacia, Lund, Sweden, 35\% efficiency). Radioactivity measured in the presence of $1000 \mathrm{nM}$ dexamethasone was regarded as nonspecific binding.

\section{Estrogen receptor - uterus cytosol}

$300 \mu \mathrm{g}$ cytosolic protein was incubated with $5,2.5,1.25,0.62,0.31,0.15$ and $0.07 \mathrm{nM}$ 2,4,6,7- ${ }^{3} \mathrm{H}$-estradiol (Izinta, Budapest, Hungary, $3.2 \mathrm{TBq} / \mathrm{mmole}$ spec. activity) in the absence or in the presence of 1000-fold molar excess of unlabeled ligand (Organon, Oss, Holland). Condition of incubation, termination of the reaction and counting were identical to those of receptor assay on thymus cytosol.

\section{Analysis of receptor-results}

Analysis of results were carried out by the computer program EBDA and LIGAND written by McPherson $(23,24)$. EBDA was used to process raw data. 
LIGAND (non-linear curve fitting program) was used to obtain final parameter estimates. Statistical analysis of the final parameters was calculated by the computer program DATAANALYSIS V.1.0. Statistical and Design Services, 1985; analysis of variance, simple F-test comparison.

\section{Results and Discussion}

Tamoxifen is a synthetic non-steroid molecule with high affinity to estrogen receptors. It can antagonize estrogen effect in some cases, in other cases it is agonistic $(19,21)$. Given neonatally to females in a single dose, it provokes imprinting with a subsequent decrease of thymic glucocorticoid and uterine estrogen receptor binding capacity (13). In addition it dramatically decreases the sexual activity (12). Considering that perinatal treatment with tamoxifen causes an immediate neuronal loss in the sexually dimorphic nucleus of the preoptic area (26) and defeminizes female's corpus callosum (16), the effect on sexual activity is understandable. These facts made reasonable to study the imprinting effect of tamoxifen treatment in the secondary critical period, at late adolescence (2).

Allylestrenol (Gestanon, Organon), which is used in human therapy for protecting endangered pregnancies, in animal experiments causes decrease of receptor binding capacity (14) and an extreme loss of sexual activity (15) in adult rats after perinatal imprinting. Since many pregnant women had been treated with this drug it seemed to be plausible to study the combined (allylestrenol and tamoxifen) effect in our animal model.

In the present experiments the Meyerson index as well, as the lordosis quotient of pubertally tamoxifen treated animals were significantly ( $\mathrm{p}<0.01)$ less (from $40 \%$ decreased to about 10\%) than those of the controls (Figs 1 and 2), soon after the treatment.

Table I

Saturation analysis of the thymic glucocorticoid and uterine estrogen receptors $( \pm S D)$ of perinatally allylestrenol treated and non-treated; and at adult age tamoxifen treated and non treated adult female rats

\begin{tabular}{llll}
\hline Group & Receptor & $\mathrm{K}_{\mathrm{d}} \mathrm{M}^{-10}$ & $\mathrm{~B}_{\max } \mathrm{M}^{-10}$ \\
\hline Control & estrogen & $9.08 \pm 0.87$ & $7.37 \pm 1.27$ \\
TAM-treated & estrogen & $7.42 \pm 0.87$ & $6.91 \pm 1.84$ \\
ALL+TAM treated & estrogen & $8.78 \pm 4.55$ & $7.13 \pm 3.47$ \\
& & $\mathrm{~K}_{\mathrm{d}} \mathrm{M}^{-9}$ & $\mathrm{~B}_{\max ^{-9}}$ \\
Control & glucocorticoid & $8.90 \pm 3.42$ & $3.36 \pm 1.39$ \\
TAM-treated & glucocorticoid & $10.60 \pm 1.40$ & $3.17 \pm 0.75$ \\
ALL+TAM treated & glucocorticoid & $12.90 \pm 0.14$ & $3.91 \pm 0.34$ \\
\hline
\end{tabular}




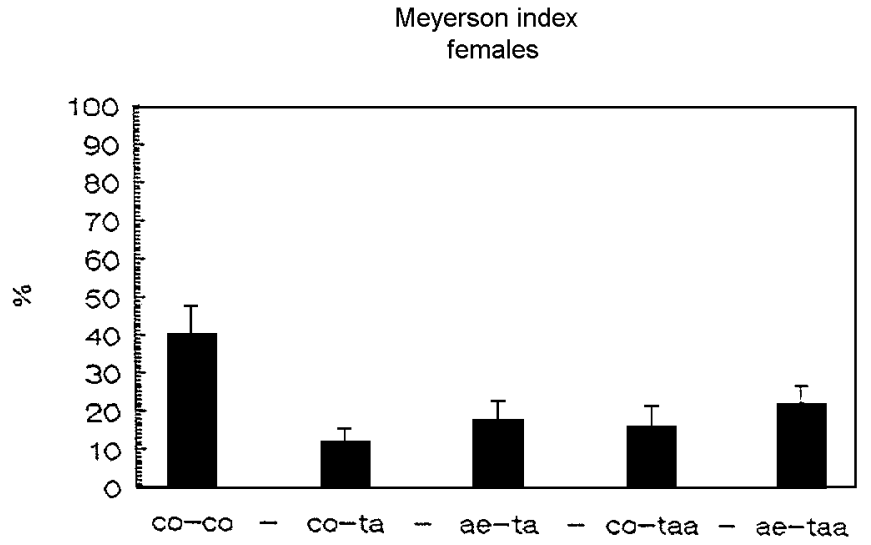

Fig. 1. Meyerson index of female rats, neonatally allylestrenol treated or not treated and tamoxifen treated or

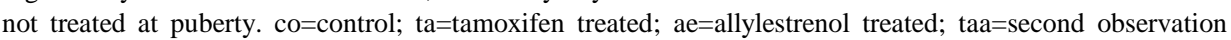
four to six weeks after the end of pubertal treatment

\section{Lordosis quotient}

females

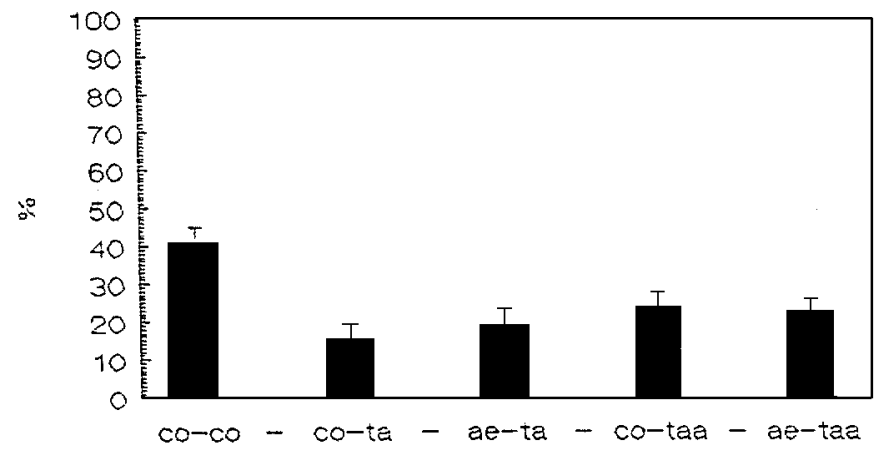

Fig. 2. Lordosis quotient of female rats, neonatally allylestrenol treated or not treated and tamoxifen treated or not treated at puberty. $c o=$ control; ta=tamoxifen treated; ae=allylestrenol treated; taa $=$ second observation four to six weeks after the end of pubertal treatment

Similar results had been observed in the neonatally allylestrenol treated and later tamoxifen treated animals $(\mathrm{p}<0.01)$, without significant difference to the only tamoxifen treated females. Between four and six weeks after the end of tamoxifen treatment similar results were won, which calls attention to the prolonged behavioral effect of tamoxifen imprinting. 
The saturation analysis of the thymic glucocorticoid and uterine estrogen receptors did not demonstrate significant differences (to control) after pubertal tamoxifen treatment or after neonatal allylestrenol and pubertal tamoxifen treatments in the affinity or density of receptors (Table I) in the five and a half months old animals. This means that in the adolescence different receptors (brain, thymus and uterus) of the same hormone (estrogen) are differently influenced by tamoxifen imprinting and brain receptors retained their sensitivity, while the "peripheral" receptors lost it. It seems to be likely that this sensitivity is also imprinter-dependent, since in earlier experiments (11) nandrolone provoked imprinting of the "peripheral" receptors.

As it was demonstrated, neonatal allylestrenol treatment did not influence the tamoxifen effect on the sexual behavior, there was not a sum of the negative influences. Moreover, pubertal tamoxifen treatment compensated the negative effect of perinatal allylestrenol treatment (demonstrated in earlier experiments (14) on the receptor's binding capacity.

\section{Acknowledgements}

This work was supported by the National Research Fund (OTKA-T-029002), Hungary. The authors thank Ms. Katy Kallay and Ms. Andrea Kovács for the expert technical work.

\section{REFERENCES}

1. Arriaza CA, Mena MA, Tchernitchin AN: Prenatal androgenisation selectively modifies some responses to oestrogen in the prepubertal rat uterus. J. Endocrinol. 120, 379-384 (1989)

2. Baker DEJ (1979): Reproduction and breeding. In: The laboratory rat, eds. Baker HJ, Lindsey JR, Weisbroth H, Academic Press, New York, pp. 153-168

3. Bern HA, Gorski RA, Kawashima S: Long term effects of perinatal hormone administration. Science 181, 189-190 (1973)

4. Bern HA, Edery M, Mills KT, Kahrman AT, Mori T, Larson L: Long term alterations in histology and steroid receptor levels of the genital tract and mammary gland following neonatal exposure of female $\mathrm{BALB} / \mathrm{cCrgl}$ mice to various doses of diethylstilbestrol. Cancer Res. 47, 4165-4172 (1987)

5. Csaba G: Phylogeny and ontogeny of hormone receptors: the selection theory of receptor formation and hormonal imprinting. Biol. Rev. 55, 47-63 (1980)

6. Csaba G: The present state in the phylogeny and ontogeny of hormone receptors. Horm. Metab. Res. 16, 329-335 (1984)

7. Csaba G: Receptor ontogeny and hormonal imprinting. Experientia 42, 750-759 (1986)

8. Csaba G: Interactions between the genetic programme and environmental influences in the perinatal critical period. Zool. Sci. 8, 813-825 (1991)

9. Csaba G: Phylogeny and ontogeny of chemical signaling: origin and development of hormone receptors. Int. Rev. Cytol. 155, 1-48 (1994)

10. Csaba G: Hormonal imprinting: its role during the evolution and development of hormones and receptors. Cell Biol. Int. 24, 407-414 (2000) 
11. Csaba G, Nagy SU: Influence of the neonatal suppression of TSH production (neonatal hyperthyroidism) on response to TSH in adulthood. J. Endocrinol. Invest. 8, 557-561 (1985)

12. Csaba G, Inczefi-Gonda Á, Dobozy O: Hormonal imprinting by steroids: a single neonatal treatment with diethylstilbestrol or allylestrenol gives rise to a lasting decrease in the number of rat uterine receptors. Acta Physiol. Hung. 67, 207-212 (1986)

13. Csaba G, Karabélyos Cs, Dalló J: Fetal and neonatal action of a polycyclic hydrocarbon (benzpyrene) or a synthetic steroid hormone (allylestrenol) as reflected by the sexual behavior of adult rats. J. Developm. Physiol. 19, 67-70 (1993)

14. Csaba G, Inczefi-Gonda Á: Effect of neonatal treatment with mifepristone or tamoxifen on the binding capacity of the thymic glucocorticoid or uterine estrogen receptor of adult rats. Data on the mechanism of hormonal imprinting. Life Sci. 67, 2531-2537 (2000)

15. Csaba G, Karabélyos Cs: Effect of a single neonatal treatment (hormonal imprinting) with the antihormones, tamoxifen and mifepristone on the sexual behavior of adult rats. Pharm. Res. 43, 531-534 (2001)

16. Fitch RH, Berrebi AS, Cowell PE, Schrot, LM, Denenberg VH: Corpus callosum: effects of neonatal hormones on sexual dimorphism in the rat. Brain Res. 515, 111-116 (1990)

17. Gibson DFC, Roberts SA, Evans GS: Changes in the hormone depedency of epithelial cell proliferation in the genital tract of mice following neonatal oestrogen treatment. Eur. J. Cancer 27, 1295-1301 (1991)

18. Gray-Nelson K, Sakay I, Eitzman B, Steel T, McLachlan J: Exposure to diethylstilbestrol during a critical developmental period of the mouse reproductive tract leads to persistent induction of two estrogen regulated genes. Cell Growth Diff. 5, 595-606 (1994)

19. Grese TA, Dodge JA: Estrogen receptor modulators: effects in non-traditional target tissues. Ann. Rep. Med. Chem. 31, 181-190 (1996)

20. Iguchi T: Cellular effects of early exposure to sex hormones and antihormones. Int. Rev. Cytol. 139, 1-57 (1992)

21. Kaplan-Kraicer R, Kostovetsky I, Bardin CW, Shalgi R: Tamoxifen and RU39411 synergize with mifepristone to produce pregnancy loss by increasing embryo transport (rat). Contraception 53, 367-373 (1996)

22. Madlafousek J, Hlinák Z: Sexual behavior of the female laboratory rat: inventory, patterning and measurement. Behavior 63, 129-174 (1977)

23. McPherson GA: Analysis of radioligand binding experiments and microcomputing systems. TIBS 41, 369-370 (1983)

24. McPherson GA: Analysis of radioligand binding experiments: a collection of computer programs to the IBM PC. J. Pharmacol. Method 14, 213-218 (1985)

25. Tchernitchin AN, Tchernitchin N: Imprinting of paths of heterodifferentiation by prenatal or neonatal exposure to hormones, pharmaceuticals, pollutants and other agents and conditions. Med. Sci. Res. 20, 391-397 (1992)

26. Vancutsem PM, Roessler ML: Neonatal treatment with tamoxifen causes immediate alterations of the sexually dimorphic nucleus of the preoptic area and medial preoptic area in male rats. Teratology 56 , 220-228 (1997) 